Peer-reviewed article

ISSN: 2162-3104 Print/ ISSN: 2166-3750 Online

Volume 5, Issue 2 (2015), pp. 175-187

(C) Journal of International Students

http://jistudents.org/

\title{
Summer Study-Abroad Program as Experiential Learning: Examining Similarities and Differences in International Communication
}

\author{
Kenneth J. Levine, PhD \\ Michelle E. Garland (Doctoral Student) \\ School of Communication Studies \\ University of Tennessee (USA)
}

\begin{abstract}
This paper examines how the study-abroad experience enhances intercultural communication competence. This study used Bennett's (1986, 1993) model of ethnorelative typology of acceptance, adaptation, and integration to explore intercultural communication competency. Central to intercultural communication competency is intercultural sensitivity and modified perceptions of cultural differences. A pre-test/post-test open-ended questionnaire design was utilized to uncover what was learned by students while participating in a four-week summer study-abroad program in Paris and Brussels. Based on 110 participants over 16 years, results indicated that both sensitivity to and understanding of cultural differences are heightened as a result of the study-abroad experience. Further, these findings provided support for outcomes showing attainment of intercultural communication competency learning objectives.
\end{abstract}

Keywords -- Study-Abroad; Experiential Learning; Intercultural Sensitivity; International Communication; Assessment

Colleges and universities nationwide are adding courses on international and intercultural communication to their curriculum as a way to prepare their students for the global workplace which awaits them. As part of this process, both on-campus and study-abroad courses have been initiated and expanded to enhance students' knowledge of and sensitivity toward other cultures (Driskill, Arjannikova, \& Schneider, 2010). Study abroad courses specifically allow for a more authentic educational experience, "an opportunity of observing society by living in physical and social conditions utterly unconnected with his own" (Battsek, 1962, p. 228). While international and intercultural campus initiatives are important and beneficial, nothing can compare with the 
actual experience of being somewhere different and needing to communicate effectively.

According to Hooper (2000), mastery of the process of cross-cultural learning, communication, and human relations is more important than the depth to which one comes to know the culture under study. Based on prior research and instructional goals, Driskill et al. (2010) have created four categories of learning objectives to assist educators in creating effective courses: awareness, knowledge, skills/behavior, and motivation/attitudes. Specifically, these four objectives are: (1) to become more aware of one's own culture and communication styles and how they differ from that of other cultures (Gaston, 2001); (2) to understand how culture affects the communication process (Millette, Steinfatt, \& Hericks, 2000); (3) to develop analytical skills in examining intercultural interactions (Pierson, 1996); and (4) to increase sensitivity to "the complexity of intercultural interactions" (Bradford \& Drzewiecka, 1997, p. 2). While the authors believe that all four categories of learning objectives are important, for the purpose of this exploratory study, awareness, knowledge, and attitudes are the central focus.

\section{Literature Review}

Central to the development of intercultural communication competency is experiential learning and situated cognition (Jacobson, 1996). Experiential learning focuses on the role of experience in the learning process as well as the role of reason operating within the context of experience. Experiential learning has personal involvement, is self-initiated, is pervasive, and is evaluated by the learner, therefore having relevance to the whole person (Schunk, 2012). Personal involvement and pervasiveness are especially important to this study as cognitions and feelings as well as behavioral and attitude changes are explored in relation to the study abroad experience.

In the context of study abroad specifically, situated cognition plays a critical role in the experiential learning process because, according to this theory, learning should be authentic to the context of study and situated in a community of practice. "Learning is a co-constructed process in which all participants change and are transformed through their actions and relations in the world" (Driscoll, 2005, p. 159). Schunk (2012) noted that situated cognition is important to the development of competency. The heart of situated cognition in the context of this study is reflected in the following statement by Battsek (1962).

There is the intrinsic value of being forced into social situations where the security and protection of the home is absent and of gaining an awareness of situations, which does not often come to a young person unless he is forced to take a stand on social matters that have no real meaning for him in his own surroundings. (p. 229)

Lindsey (2005) presented similar findings, stating "study abroad offers a unique opportunity for students to confront both differences and similarities in many aspects of culture and values, as well as develop specific skills in multicultural competence" (p. 232), a process that requires dialogue and discussion, according to Danzig and Jing (2007). In a similar study, Anderson and Rexeisen (2006) found that students who participate in a short-term, nonlanguage-based study abroad program were better able to accept and adapt to differences within culture resulting in improved intercultural sensitivity at the conclusion of such programs.

These findings present a clear implication for the need to measure outcomes centered on

Summer 2015

http://jistudents.org

Volume $5 \bullet$ Issue 2 
the goal of intercultural communication competency. In the context of experiential learning in study abroad, however, cognition is limited by what the students choose to acknowledge, picking up on what interests them most. This selectivity can impact the outcomes of developing sensitivity through their selective observations.

Intercultural sensitivity, as defined by Hammer, Bennett, and Wiseman (2003) is "the ability to discriminate and experience relevant cultural differences" (p. 422). This concept is central to this study, which seeks to include and examine the communication variable in exploration of the attainment of intercultural sensitivity. Bennett (1993) stated that "probably one of the most threatening ideas encountered by students is this concept of difference and the implications this concept brings along with it" (p. 181). Thus, central to these categories of awareness, knowledge, and attitudes are the concepts of ethnocentrism and ethnorelativism. Chaney and Martin defined ethnocentrism as "the belief that your own cultural background, including ways of analyzing problems, values, beliefs, language, and verbal and nonverbal communication, is correct" (2011, p. 10). In and of itself, ethnocentrism is not negative. It is when biases are revealed that the negativism of enthnocentrism becomes apparent. According to Pahnos and Butt (1992), these biases can lead to stereotyping, separatism, discrimination, and scapegoating. This challenge stems from the recognition that these cultural differences make students reflect and critique their own worldviews. In many cases, students must step outside of their comfort zone and consider realities that are very different from their preconceived notions of reality. In the globalized world, students come to recognize their own ethnocentrism.

The Bennett model shows that the stages of ethnocentrism lead directly into the stages of ethnorelativism. According to the model, ethnorelative orientation includes concepts of acceptance ("the state in which one's own culture is experienced as just one of a number of equally complex worldviews"), adaptation ("the state in which the experience of another culture yields perception and behavior appropriate to that culture"); and integration ("the state in which one's experience of self is expanded to include the movement in and out of different cultural worldviews") (Hammer et al., 2003, p. 425). According to the ethnorelativist perspective:

Differences are no longer threatening. It is no longer a question of preserving one's cultural reality but rather of creating new categories that allow for the coexistence of diverse cultural realities. To evolve, difference is sought rather than feared. (Olson \& Kroeger, 2001, p. 122)

Central to the integration stage is contextual evaluation, which is when "the individual is able to analyze and evaluate situations from one or more chosen cultural perspectives" (Olson et al., p. 123).

This study used the Bennett's ethnorelative typology of acceptance, adaptation, and integration to explore intercultural communication competency with the assumption that the completion of the stages of ethnocentrism are reflected in the stages of ethnorelativism. Central to intercultural communication competency is intercultural sensitivity and modified perceptions of cultural differences, as reflected in the literature. Taken together, the following research questions are posed:

RQ1: Do students reflect increased intercultural sensitivity upon the conclusion of the study abroad program?

RQ2: Do students reflect modified understanding of cultural differences upon the conclusion of the study abroad program? 


\section{Method}

This exploratory study utilized a pre-test/post-test open-ended questionnaire design to uncover what was learned by the students while participating in a four-week summer study-abroad program.

\section{Subjects and Background}

Respondents were 110 (82 female, 28 male) undergraduate and graduate students participating in a four-week summer study-abroad program entitled "International Communication and the International Workplace." The program has been sponsored by four different institutions, therefore the students included in this study were from a mid-sized Midwestern university, a large Midwestern university, a large Southeastern university, and a small New England liberal arts college. All but three of the respondents were United States citizens at the time of their participation in the program. The three non-U.S. students were from Brazil, (female), China (female) and Turkey (male) and were enrolled as full-time students in a United States university during their participation in the program. Each of these students were enrolled in different years of the program; there were never multiple non-U.S. students on any year's program.

The survey asked very few demographic questions as these instruments were used as part of class instruction. Further, there were no items regarding language fluency (French or otherwise) since a foreign language was only a requirement for communication majors at one of the four universities which sponsored the program. As such, there is no information regarding fluency. Anecdotal evidence suggests that there have been very few students with a fluency in French, however many had one or two years of college-level instruction in Spanish. The classes associated with the program were taught in English.

\section{Procedure}

Prior to departure, the students were assigned to answer an "International

Communication Questionnaire" created by the instructor specifically for this program as an assessment tool to understand what the students truly learned from the study-abroad experience. In the instructions, students were asked to answer the questions to the best of their knowledge, but not to undertake any research. Further, if they did not know the answer, the students were told that it was okay to leave the response blank. The survey was completed and returned to the professor prior to departure.

To determine cultural sensitivity, the following two questions were asked: (1) What are the role prescriptions (how people are supposed to behave) of a North American? and (2) What are the role prescriptions of a French person? When the instrument was given to the first group of students, the question used the term "American" rather than "North American." There were questions regarding whether the term "American" also meant Central and South American, as some of these issues are covered in their Spanish language courses. As such, the term was changed to "North American" to insure that those students with a level of knowledge of Spanish language and culture understood that the respondents were to use their own culture in answering the question.

Using the Bennett et al. (2003) definition of intercultural sensitivity, responses regarding role description reflect the student's "ability to discriminate and experience relevant cultural differences" (p. 422). This description and discrimination therefore indicate understanding. To 
determine the level of understanding of cultural differences, the following two questions were asked: (1) What is the biggest difference between the communication style of a North American and that of a French person?; and (2) what is the biggest difference between the organizational communication style of a North American and that of a French person? At the conclusion of the program, the same questionnaire was included as part of the final exam. The only difference was that instructions for the final exam required students to answer each question.

These data were initially collected solely as feedback for the instructor. As such, this project qualified for exempt status from IRB approval as it was comprised of existing data; these data had been used as part of an educational experience, and all identifying information has been removed prior to analysis.

Qualitative software (SPSS Text Analysis for Surveys) was utilized for the analysis of these data. This program both performed word counts and also created categories based on associations between and among words within close proximity to other terms. The top five responses per category were included in the results.

\section{Findings}

Research question one asked if students reflect increased intercultural sensitivity upon the conclusion of the study abroad program. To understand the change in perspective, the answers to the pre- and post-test responses of the following questions were compared: "What are the role prescriptions of North Americans?" and "What are the role prescriptions of the French?"

There were 34 students that failed to respond to the pre-test question regarding the role prescriptions of North Americans. Of those that did respond, most students responded with short answers and an awareness of certain aspects of the U.S. culture. For example, one respondent answered that "there are fairly few - there is a great deal of value placed on being an individual and free spirit" [1]. The three most common attributes mentioned regarding the U.S. were courteous (19 instances); friendly (18 instances) and loud (13 instances). When loud was included in the answer, the overall response had a negative tone; for example "North Americans are supposed to behave as loud, obnoxious, smiling and very demanding or controlling (selfcentered) people" [respondent 26] and "They are loud, obnoxious and ethnocentric" [respondent 3]. The answers also addressed the perceived attributes of North Americans, which also had a negative tone; for example "North Americans are often thought of by the French as big people, sloppily dressed, rude, disrespectful, and loud" [respondent 33] and "According to Europeans: loud, obnoxious, rude, overzealous, wasteful, stupid" [respondent 62].

There were also positive views of the U.S. culture in the responses to the first question. "Friendly" as an adjective was most often combined with polite; for example "In America, people are generally 'supposed' to behave politely and friendly to people, even if they do not know them" [respondent 77]; and "People should be friendly, polite, kind, and courteous" [respondent 82]. One respondent addressed differences in role prescriptions within the U.S. In different parts of the U.S. there are different standards for behaving but in general people expect us to be kind, well-mannered, and friendly." Interestingly, one American respondent used the pronoun "they" when describing their own, U.S., role prescriptions: "They're supposed to be friendly and nice, polite to people" [respondent 55].

When asked about the role prescriptions of the French, there was considerably more variability. The most common responses were quiet and rude (9 instances each). There were 35 students that failed to respond to this question during the pre-test. Most respondents answered 
with a neutral tone when reporting "quiet" as a role prescription; for example, "Quiet, they keep to themselves until they get to know you" [respondent 6] and "French are quiet, compact, and are more proper" [respondent 23]. However, both positive and negative toned responses were also found; for example, "Quiet, rude" [respondent 26]; and "Bien cleve - polite, courteous, quiet, not money oriented; more spontaneous; live for today" [respondent 57]. One respondent addressed a direct comparison of the role prescriptions of North Americans and French: "Just the opposite of Americans. French are supposed to be reserved, quiet, and fit into the mainstream" [respondent 22].

When "rude" was reported, the answers often included additional adjectives with negative connotations; for example, "According to Americans: rude, snide, snotty, impatient, condescending, smelly, socialist" [respondent 62]. However, with some of these comments, disclaimers and other political politeness tactics were used; for example, "French people are stereotypically thought of by Americans as arrogant, rude, fashionable, different. Really they care about their country and are helpful when treated with respect and politeness" [respondent 33]. Again, the software program found few overlaps between the terms suggesting that there was tremendous variability in the answers. As this was the pre-test, this amount of variability is not surprising.

The post-test findings for North American role prescriptions were, at the surface level, consistent with the pre-test findings among the students. The number of non-responses for the post-test dropped to nine. The most common responses were "friendly" (26 instances) and "loud" (25 instances). The next most common responses were "smile" and "courteous" (14 instances each). When "friendly" was reported, answers often paired "friendly" with the second tier themes - "smile" and "courteous". For example; "It is expected that North Americans be [sic] friendly when they are introduced to someone. They believe they should smile and shake hands to be personable" [respondent 8]; "North Americans are usually considered to be friendly because they smile at everyone and we are always supposed to be in a hurry." [respondent 29]; and "Expected to be independent, friendly, \& courteous. Show manners \& dress \& act according to the situation we are in" [respondent 105]. Because the responses varied between positive, negative and neutral, there was no one theme for these responses. The post-test answers additionally provided more depth in the responses; for example, "North Americans are supposed to be independent, courteous and smile even at strangers, brave and take chances. We are supposed to go after our dreams and even if we fail we are still respected for trying." [respondent 107].

While "friendly," "smile," and "courteous," were positive prescriptions, the overall tone of the responses was considerably more negative than responses to the pre-test, specifically with regards to comments including the prescription of "loud". For example, "Americans are loud, obnoxious, and take up lots of space. Many expect the world to be like America and are put out when it is not. Attitude could describe many of us." [respondent 18]; "North Americans are typically loud, rude, ignorant, friendly; North Americans watch too much TV and don't spend enough time developing close relationships" [respondent 24]; "Loud, rude, obnoxious, oblivious, dumb, wasteful, arrogant, violent, warmongers" [respondent 62]; and "We are supposed to be loud and obnoxious" [respondent 21]. An interesting note regarding respondent $\# 21$, he was one of the only people to use the term "we" rather than "they" when discussing his own culture. Most of the other respondents placed a distance between themselves and their own cultural descriptors.

The post-test findings for French role prescriptions were also consistent with the pre-test

Summer 2015

http://jistudents.org

Volume $5 \bullet$ Issue 2 
findings among the students, specifically at the surface level. Regarding the post-test for the French, the terms quiet and rude both appeared 14 times, though in very different contexts than in the pre-test. When reporting "quiet" for example, "The French seem to be more conservative than North Americans. They are quiet. They deem relationships to be of great importance and the relationships they make tend to last." [respondent 13]; "They are much more quiet than we are. The French act more formal towards one another and are more respectful of all people regardless of social class" [respondent 109]; and "Socially acceptable norms are to be quiet and reserved, to only show emotion to those who you genuinely care about" [respondent 92]. These responses indicate an understanding and appreciation that pre-test responses lacked.

When "rude" was reported, the overall tone was negative. Interestingly, the disclaimers and political correctness found in the pre-test were rarely included in the post-test responses. For example, "They are rude and they smell. They have no customer service skills and they work for the better of their group. They want to preserve their own culture" [respondent 6]. However, some responses did address the issue of stereotypes; for example, "The North American often thinks of the French as being rude, arrogant, fashionable, sexual, smelly, wine drinkers, gourmet chefs, fine food eaters - again stereotypes and generalizations" [respondent 33] and "They are reserved, quiet, and rude. They want to preserve their culture and are not always friendly to outsiders." [respondent 3]. In these responses, we can begin to see that while negative on their face, the answers suggest that there is more understanding of the differences between cultures after spending the month studying in Europe. This can been seen in the response of \#102, "Pushy and rude. Or seemingly so to Americans. To the French, I would see my role as just trying to get where I was trying to go through a city of tourists."

In her ability to recognize her own bias, respondent \#102 serves as an example that students learn sensitivity and reflect ethnorelative orientation through indications of acceptance, adaptation, and integration, as identified in Bennett's model (1986, 1993). Thus, to answer Research Question \#1, there appears to be more understanding of both their own and the French culture as a direct result of participating in the study-abroad program.

Research question two asked if students reflect modified understanding of cultural differences upon the conclusion of the study abroad program. To understand the change in perspective, the answers to the pre- and post-test responses of the following questions were compared: "What is the biggest difference between the communication style of a North American and that of a French person?" and "What is the biggest difference between the organizational communication style of a North American and French person?"

On the pre-test, when the students were asked "What is the biggest difference between the communication style of a North American and that of a French person?" they truly had no background understanding of this information. Thirty-three students failed to respond to this question, and there was considerable variability in the answers of those that did respond. Volume was the most prevalent answer with adjectives such as "louder" (8 instances), "loud" (6 instances), and "quiet" (5 instances); for example, "I think the biggest difference between NA and French communication styles is not only volume but also how animated a person is. As stated above, I think NA are more eccentric in their communication. Also much louder" [respondent 76].

"Language" and "formal" were also among the most prevalent answers with six and five mentions respectively. Language, however, was used in two separate contexts; for example, "The language itself" [respondent 3] and "North Americans are very lazy with language. We don't even speak our own language correctly. We use a lot of slang. French are very proud of 
their language and also speak it correctly" [respondent 24]. When "formal" was used in the answer, the tone of the response was mixed; for example, "The French are more formal. No 'Hey'. Must say 'Bonjour' first or some other polite comment before asking a question" [respondent 30], and "French is more impersonal and formal, North American is more relaxed and friendly. The French find Americans to be downright rude" [respondent 89]. Only one student used formal to describe the communication style of North Americans.

That said, stereotypes of both Americans and the French were apparent in the responses. For example, "Seriously Americans speak before thinking. Usually unprepared speech. French people usually do not stutter as much and take time to think about their speech" [respondent 26]; "The biggest difference between the communication style of a North American and that of a French person is motivation. The Americans communicate individually, the French communicate a collective identity" [respondent 31]; "The French use a small bubble of space and speak very quietly to each other. Americans tend to speak loudly and use a lot of small talk which the French don't." [respondent 18]; and "We are friendly to just about everyone and the French are only friendly to their friends. Looking eye to eye is big in America, but not in France" [respondent 27].

In terms of their knowledge of organizational communication across cultures, the variability was even more pronounced than for interpersonal communication. Few respondents demonstrated a solid understanding of organizational communication differences. Those that did answered "the French person does not socialize with their co-workers the way that Americans do." [respondent 30]; "French do not talk to bosses higher up on the hierarchical chart whereas Americans monopolize on friendship to move up in the world." [respondent 26]; and "The biggest difference is that French organizations have a hierarchy system. Hence, when someone wants to voice a complaint, for example, he has to go through correct channels, i.e., his immediate boss. In America, there is no hierarchy system in organizations. Differences in ranks are not as pronounced as they are in France" [respondent 41].

Beyond the organizational hierarchy structure, other common responses touched on formality and time. When the term "formal" was used, it was attributed to the French. Interestingly, when the terms "relaxed" and "laid-back" were used, they were also attributed to the French in all cases but one. However, this laid-back, relaxed nature tended to represent the nature of the work environment as opposed to the communication styles specifically. When "time" was used, it was used in terms of pace and value. For example, "Time means money to us, but French take their time to get things done" [respondent 5], and "If organizational communication style means how they organize their time, then the French are known as being a highly efficient society that is very well organized. 'Hustle and Bustle' is the most common way of life for a typical North American" [respondent 52].

In the post-test, there was much more of an understanding of interrelationships between communication topics in understanding the similarities and differences between the U.S. and the French organizational culture. Several prominent outcomes were expressed in relation to interpersonal communication: context, time, volume, nonverbals, hierarchy and relationships. In regards to context, the responses addressed the differences of high- and low-context cultures. For example, "Besides language the biggest difference is that an American's communication style is based on low context culture and the French communication style is based on high context culture. Therefore Americans communicate directly, think and act in a linear matter controlled by time constraints. The French however, deal completely with relationships, codes, flexible time, and communicate in a circular mode of thinking and acting." [respondent 33] and 
"The biggest difference is that North America is a low-context culture, meaning the communication is direct, clear, linear and verbal, whereas France is a high-context culture, in which communication is more coded, circular, and indirect. In France, the messages come from body language, the setting, and the relationship between the people involved." [respondent 41]. Similar to pre-test results, volume and nonverbals such as gestures, body movement, and facial expressions were among the most prominent themes expressed in the responses. However, in regard to post-test results, the responses were more thorough and detailed indicating increased understanding. Examples of these learning outcomes were "Americans are louder, more friendly and more direct in almost any setting" [respondent 3]; and "Well the first and most obvious is volume. North Americans tend to be much louder. The French tend to be quieter, but are more expressive when loud. Gestures are used by both, but facial expression and body language plays a larger role to the French than North Americas." [respondent 60] One respondent addressed volume and nonverbals with special emphasis on space.

I think we as Americans come across much more relaxed and unsophisticated than the French. Americans slouch and are not respectful of others' space by taking up a lot and are loud as well. French are much more reserved and quieter. They take up less space, talk quieter, sit straight and within their own space [respondent 37].

This is one of the few respondents who seemed to look at their in-group, Americans, in a more negative light at the conclusion of study abroad. Others, however, also seem to correlate the French with a more positive perception. "Americans are very loud and French are more quiet. The French tend to look more upset or mad, but once you get to know them they are very nice." [respondent 87]. What is reflected here is not only intercultural sensitivity, again defined as "the ability to discriminate and experience relevant cultural differences" (Hammer et al., 2003, p. 422) but also ethnocentrism, which includes concepts of acceptance, adaptation, and integration.

It is important to note that when discussing nonverbal communication, and in many cases verbal communication, the connection to building and sustaining relationships is drawn. For example, "The fact that Americans are friendly. They will smile or talk to anyone. It does not matter if the relationship is close or not." [respondent 28] and "The French need to form a relationship with a person before they'll accept you and basically communicate with you. The Americans jump right in and talk with you and smile at you whereas the French need time to get to know you." [respondent 6].

Relationships, however, also played a prominent role in the responses to the question regarding difference in organizational communication, as seen in the response of respondent \#42.

Closer relationships verses independent workers: an American may communicate with the boss and a couple of coworkers. No close, intimate conduct is expected between employees and bosses. However in France, on the other hand, an employee must greet every employee and boss. Drinking out with the boss or engaging in more intimate settings (for example going to a sauna with coworkers and your boss) are not uncommon for French people working together.

Other examples of the learning outcome were "We are more individually productive whereas in France projects are completed because of the vast network of people" [respondent 2]; "I think this relates to the time issue. Americans base their business on time and want to make 
money. The French don't mind things taking a little longer as long as they can keep and build relationships. It is more important to the French to have relationships in business than meeting the deadline at work." [respondent 37]; and "French work on a large part on a social aspect, creating relationships is very important, also the work standards are lower because it is hard to fire someone after the 6 month trial period. While in America it's more business all the time, time is important and trying to better oneself in the workplace." [respondent 80].

Some responses also addressed the differences in the perceptions and realities of the job and job duties. For example, "In an organizational style, North Americans are more assertive, brain stormers, go-getters. French are more reserved, less brainstorming. North Americans want to climb the corporate ladder. French are satisfied with the same job for years and years." [respondent 12], and "The largest difference between organizational communication of a North American and a French person is the desire to do the task well. A French person takes the project personally responsible and puts a great deal of effort on the project. They expect others to do the same and are quick to point out what others have not done if something is wrong. Americans see it as a job, not a personal investment."[respondent 26].

A third example reads:

The role of subordinates and the way they deal with university is different than ours. They are tracked into either high school graduates, trade school, or university. They have virtually no choice. This is directly opposite of the American way of life. Americans are raised to be whatever they want. This has a big effect on how subordinates are treated. They're expected to work and follow orders. Americans offer opinions and develop relationships with their bosses." [respondent 104].

A fifth prominent learning outcome in relation to organizational communication expressed in the answers was hierarchy, as reflected in the above and following responses. According to one respondent, "Organizational communication is decentralized. - Communication within a company is very horizontal, with peers from different departments collaborating with each other as opposed to a centralized approach where employees merely follow orders from someone higher up. French organizational communication is hierarchical, with each employee following someone else that is higher in the chain of command" [respondent 75].This dichotomy is expressed by many respondents. Another wrote, the "French organization is run like a monarchy. Each decision comes from the top down, and there is no communication upward or outward. An American organization is egalitarian. Everyone knows his or her place in the organization and feels a part of the process" [respondent 61]. One respondent links the learning outcome of hierarchy with the most prominent learning outcome in regards to organizational communication, time.

The biggest difference would be the structure. In America you can move easily through the company, whereas in France there is a cell structure. You could only talk to the person above you or below you. Also, Americans work much more. It is common to arrive early, leave late and work on weekends. In France, it is common to be late and leave work at work [respondent 28].

As stated above, the most prominent of these learning outcomes was the understanding of 
the cultural difference in perception of time, specifically in regards to organizational communication. For example, "A North American lives by the clock and has a beginning and/or deadline for almost everything, while a French person lives by their own time and experiences life in a more relaxed and appreciative manner" [respondent 106]; and "Americans are organized by time. For example at $12 \mathrm{I}$ have an appointment, etc. French organize according to how they feel. For example I will get there around 12. To Americans time is of the essence. To French time is of convenience" [respondent 58]. Another response echoed this understanding of time while also addressing another prominent learning outcome, space.

The biggest difference between organizational communication style is the way the French perceive time and deal with space as compared to America. The French are very relaxed and they value every minute. They are also very space efficient and will keep to themselves at the workplace. Americans are completely different and are very time efficient and organized. However, in the matter of space one typically is relaxed and spread out, owning the space they claim. The French also care how the task is completed and will extend deadlines to get perfection in their work. An American will get the deadline completed and prepare a final product just to finish on time and be in good graces with the employer [respondent 52].

Taken together, there is little doubt that these post-test responses demonstrate a much more solid understanding of the similarities and differences between interpersonal and organizational communication styles in the United States and France in addition to how role prescriptions of each impact communication.

While not examined as a research question, a word count was calculated for these four questions and the means were examined using a one-sample t-test. It was the belief of the authors that increased word counts per question would indicate increased knowledge and understanding. Stated more simply, if students have an increased knowledge and understanding, they will likely have more to say. In all four cases, the mean number of words used in the posttest was significantly higher than in the pretest. More specifically, in answering "What are the role prescriptions of a North American?" the mean word count increased from 10.77 to 21.12 from pre- to post-test, an increase that was statistically significant $(\mathrm{t}(91)=7.429, p<.000)$. In answering "What are the role prescriptions of a French person?" the mean word count increased from 10.32 to 20.67 , an increase that was statistically significant $(t(91)=7.230, p<.000)$. In answering "What is the biggest difference between the communication style of a North American and that of a French person?" the mean word count increased from 13.45 to 23.76, an increase that was statistically significant $(\mathrm{t}(91)=11.872, p<.000)$. In answering "What is the biggest difference between the organizational communication style of a North American and that of a French person?" the mean word count increased from 13.03 to 35.75 , an increase that was statistically significant $(\mathrm{t}(91)=12.21, p<.000)$.

\section{Discussion and Conclusion}

The goal of study-abroad is to immerse students into a new and unfamiliar culture. Results indicate that an appreciation for and understanding of the complexities of intercultural communication can be attained through the participation in the summer study-abroad program. When done correctly, this immersion is coupled with formal learning, which explains how and 
why a communication event experienced while on the program may - or may not - have succeeded. This process is reflective of situated cognition. At the beginning of the study-abroad experience, the students need to have failed experiences from which to learn. "Why did this happen?" or "They're rude here," is, in fact, what you want to hear as feedback. From these failed experiences, learning can occur.

Observation also becomes a prime learning tool for the study-abroad student, and many of the responses, especially the non-verbal communication examples, demonstrate that the respondents were observing their environment while attempting to engage in the new setting. While the authors do not have empirical evidence that there is causality between the student's observations and the post-test responses, there was definitely an increase in knowledge. This study suggests that to be effective in another culture, people must experience it first-hand and either be observant of or instructed in how to be sensitive enough to notice cultural differences. It is hoped that this sensitivity will cause the students to be willing and able to modify their behavior. Further, these altered behaviors will be received as an indication of respect for the people of the host culture.

There is little research on why a person decides to participate in a study-abroad program. Perhaps the goal of becoming a more competent global communicator is an unwritten prerequisite for participation in a study-abroad program. If "intercultural communication is not a natural human quality" (Olson \& Kroeger, 2001, p. 124), there needs to be a desire to learn. Oftentimes, the desire is a byproduct of the study-abroad experience rather than the impetus to participate, but regardless, the outcome is the same. Once obtained, this interest in and desire to understand different cultures becomes a part of the daily experience of life. The authors encourage other study-abroad professionals to engage in research on the question of "why" students go abroad.

The important and exciting results of this study on outcomes of experiential learning through study abroad will hopefully add momentum to the expanding landscape of study-abroad opportunities. This study adds to the existing literature, which has found that while international and intercultural campus initiatives are important and beneficial, nothing can compare with the actual experience of being somewhere different and needing to communicate effectively. This learning experience fosters the type of learning that truly resonates with the students and at the same time achieves the outcomes set out at the start of the course.

\section{REFERENCES}

Anderson, P. H., \& Rexeisen, R. J. (2006). Short-term study abroad and intercultural sensitivity: A pilot study. International Journal of Intercultural Relations, 30, 457-469.

Battsek, M. (1962). A practical analysis of some aspects of study abroad. The Journal of General Education, 13, 225-242.

Bennett, M. J. (1986). Intercultural sensitivity. In J. M. Bennett (Ed.), Education for the intercultural experience (pp. 21-71). Yarmouth, ME: Intercultural Press.

Bennett, M. J. (1993). Intercultural sensitivity. In J. M. Bennett (Ed.), Principles of training and development. Portland, OR: Portland State University.

Chaney, L. H., \& Martin, J. S. (2011). Intercultural business communication (5th ed.). Boston, MA: Prentice Hall.

Danzig, A., \& Jing, W. (2007). From tourist to learner: International travel and cultural

Summer 2015

http://jistudents.org

Volume $5 \cdot$ Issue 2 
encounters as a lens for teaching and administration. ISEA, 35, 78-91.

Driscoll, M. P. (2005). Psychology of learning for instruction (3rd ed.). Boston: Pearson.

Driskill, G.W., Arjannikova, S.\& Schneider, T. (2010). Assessing intercultural communication: Models and methods. In P. Backlund, \& G. Wakefield, (Eds.), A communication assessment primer. Washington, DC: National Communication Association.

Gaston, B. (2001). COM 340: Intercultural communication. Retrieved from http://www2.hawaii.edu/ bgaston/com340.htm.

Hammer, M. R., Bennett, M. J., \& Wiseman, R. (2003). Measuring intercultural sensitivity: The Intercultural Development Inventory. In R. M. Paige (Guest Ed.). Special issue on the Intercultural Development. International Journal of Intercultural Relations, 27(4), 421443.

Hooper, D. S. (2000). Intercultural communication concepts and the psychology of intercultural experience. In M. D. Pusch (Ed.), Multicultural education: A crosscultural training approach (pp. 9-42). Yarmouth, ME: Intercultural Press.

Jacobson, W. (1996). Learning, culture, and learning culture. Adult Education Quarterly, 47, 1528.

Lindsey, E. W. (2005). Study abroad and values development in social work students. Journal of Social Work Education, 41, 229-249.

Millette, D. M., Steinfatt, T. M., \& Hericks, E. (2000). Instructor's manual and test items to accompany the textbook Intercultural Communication by Rogers, E. M., \& Steinfatt, T.M. Prospect Heights, IL: Waveland.

Olson, C. L., \& Kroeger, K. R. (2001). Global competency and intercultural sensitivity. Journal of Studies in International Education, 5, 116-137.

Pahnos, M. L., \& Butt, K. L. (1992). Ethnocentrism - a universal pride in one's ethnic background: Its impact on teaching and learning. Education, 113, 118-120.

Pierson, J. (1996). COMM 324-Intercultural Communication. (1996). Retrieved from http://www.rcf.usc.edu/jilliank/324syll.html.

Ruddock, H. C., \& Turner, D. S. (2007). Developing cultural sensitivity: nursing students' experiences of a study abroad programme. Journal of Advanced Nursing, 59, 361-369.

Schunk, D. H. (2012). Learning theories: An educational perspective (6 $6^{\text {th }}$ ed.). Boston: Pearson.

\section{About the Authors}

KENNETH J. LEVINE is an Associate Professor in the School of Communication Studies at the University of Tennessee. Dr. Levine's research agenda concentrates on international communication, organizational communication, small group communication and leadership. Dr. Levine is an advocate for the inclusion of international and intercultural material in the classroom and has organized and taught a summer study-abroad program in Paris and Brussels since 1998. E-mail: klevine1@utk.edu

MICHELLE EPSTEIN GARLAND is a doctoral student and Graduate Teaching Associate in the School of Communication Studies at the University of Tennessee. Prior to entering the doctoral program, she taught Business and Professional Communication as a Lecturer for the School of Communication Studies for six years. Her research agenda concentrates on instructional communication, student learning, and higher education assessment and evaluation. 